\title{
Evaluation of the Anti-Biofilm Effects of Biosurfactants and Silver Nanoparticles on Biomaterials Surfaces
}

\author{
Adriano Guimaraes Parreira*, Paulo Afonso Granjeiro and Cinthia Souza Mano \\ UEMG Divinópolis MG Unit, UFSJ Campus CCO University, Brazil
}

*Corresponding author: Adriano Guimaraes Parreira, UEMG Divinópolis Unit MG and UFSJ Campus CCO University, Brazil.
Received Date: February 13, 2020

Published Date: March 04, 2020

\begin{abstract}
Orthopedic implants are subject to chronic biofilm-associated infections bacteria, which can only be eradicated by traumatic implant removal accompanied by intravenous antibiotic therapy. Alternatives have been moving towards treating the surface of these materials biosurfactants to inhibit bacterial adhesion on surfaces of these implants. Biosurfactants (BS), surfactant compounds produced by microorganisms, are molecules that have a hydrophilic region, and another therefore reduce the interfacial tension between two surfaces by changing the properties of the surfaces with which they come in contact. In this work, the ability to reduce the formation of biofilms in orthopedic implants by the action of biosurfactants with and without the addition of silver nanoparticles was evaluated. Was observed that for biofilms formed by S. aureus, E. coli and E. cloacae up to $72 \%$ inhibition of biofilm formation was achieved with the use of ramnolipids on the surface of the implant parts.
\end{abstract}

Keywords: Biomaterials; Biofilm; Inhibition; Biosurfactants; Silver nanoparticles

\section{Introduction}

Orthopedic implant infections represent major complications clinical and economic impact for the patient and society at large. Review on infection arthroplasty represents a cost 2.8 times higher than the revision revision aseptic release is a cost 4.8 times higher than primary arthroplasty [1]. The estimated prevalence of infection in arthroplasty ranges in the literature from $0.5 \%$ to $7.5 \%[2,3]$. Risk factors are influenced by variables such as patient, procedure, surgeon and hospital environment characteristics $[4,5]$. Orthopedic implants are subject to chronic biofilm-associated infections bacteria, which can only be eradicated by traumatic implant removal accompanied by intravenous antibiotic therapy $[6,7]$. Alternatives have been moving towards treating the surface of these materials biosurfactants to inhibit bacterial adhesion on surfaces of these implants. Biosurfactants (BS), surfactant compounds produced by microorganisms, are molecules that have a hydrophilic region, and another therefore reduce the interfacial tension between two surfaces by changing the properties of the surfaces with which they come in contact $[8,9]$.
The main advantages of using biosurfactants compared to synthetic surfactants reside in the biodegradable nature, low toxicity and activity antimicrobial agents that, combined with surfactant activity, may not only inhibit adhesion but also the survival of contaminating microorganisms [10]. Among the known biosurfactants, we highlight the surfactin, produced by Bacillus subtilis, and rhamnolipidss, produced by Pseudomonas aeruginosa, both of a natural surfactin belongs to the class of lipopeptides and rhamnolipidss are glycopeptides [11,12].

Colonization of the implant surface by bacteria may begin at this time of the introduction of the foreign body into the organism. This is the first step towards infection development. The bacteria, once adhered to the implant, can initiate a process involving several stages culminating in the formation of biofilm, and initially the surface is conditioned by molecules present in the medium that adsorb to the material, modifying its properties, and then the adhesion of the microorganisms on this surface which, once formed, are difficult to treat since bacteria inside the biofilm are protected 
from phagocytosis and the action of antibiotics. Studies involving biofilms have revealed distinct properties, such as structured groups of cells with community characteristics. Recent advances in knowledge of genetics and molecular basis of community behavior bacteria present in biofilms point to the control of infections induced by them and, consequently, measures that inhibit or reduce bacterial adhesion, contributing to thus reducing the formation of these biofilms [13].

Infection of implantable devices often requires removal and replacement in order to prevent the development of severe complications and even lethal [4,12-19]. The microorganisms often involved in the loss of medical devices due to infection include-Staphyloccocus epidermidis, Staphyloccocus aureus and Escherichia coli. However, S. aureus and E. coli are associated with biomaterials infection metal, bone-joint and soft tissue. E. cloacae and S. epidermidis, in turn, is related to polymer infections as endocardial valves [20].

Staphyloccocus are widely distributed in nature and are part of the normal microbiota of the skin and mucosa of mammals and birds. In general, Staphyloccocus have a benign or symbiotic relationship with the host but may become pathogenic when they reach tissues by cutaneous barrier by needles, or also by direct implantation through medical prostheses [21]. Infection of bones is called osteomyelitis and is characterized by bone colonization by microorganisms including Staphyloccocus aureus, Staphyloccocus epidermidis and Escherichia coli. Bone infections associated with bodies Strangers such as prostheses and osteosynthesis devices are difficult to treat. THE Treatment usually involves evaluation, staging, etiology sensitivity and antimicrobial therapy and if necessary, debris, management of the dead space and bone stabilization [22].

In this study it was verified whether the potential of the antiadhesive activity of biosurfactants, surfactin and rhamnolipidss, against some bacteria of interest aiming at establishing the potential use of these compounds in the control of the bacterial adhesion, thus contributing as an alternative to control the adhesion on implants for use in orthopedic surgeries.

\section{Material and Methods}

\section{Production and purification of biosurfactants}

Production and partial purification of biosurfactants was performed by Cultivation of Bacillus subtilis ATCC 19659 and Pseudomonas aeruginosa ATCC isolates 25619, evaluated for the production capacity of aerobic surfactants in the M1, M2, M3 and ME mineral media containing glucose as carbon sources at $2.0 \%$ (w/v), incubated at $30^{\circ} \mathrm{C}$ in Erlenmeyer flasks on a Shaker orbital shaker at $200 \mathrm{rpm}$ in $72 \mathrm{hr}$ intervals. Following the production of biosurfactants, precipitation of the surfactants by adjusting the $\mathrm{pH}$ of the centrifuged and cell-free medium to 2.0, employing a $6.0 \mathrm{M} \mathrm{HCl}$ solution. The medium remained incubated overnight in refrigerator at $4^{\circ} \mathrm{C}$, thus completing the process of partial purification of surfactants produced.

\section{Characterization of biosurfactants}

Drop collapse test: Biosurfactant producing colonies were selected by the test analysis of gout collapse [23]. The qualitative drop collapse test was performed in wells of microplates containing 96 shallow wells. The wells of the caps were greased with $2 \mu \mathrm{l}$ of 10W-40 motor oil or olive oil and left to stand for $24 \mathrm{~h}$. In Then $5 \mu \mathrm{l}$ of the sample was dispensed into each well in triplicate and the droplet spreading evaluated one minute later. The positive result came when the droplet diameter was larger than that of a deionized water droplet used as a control negative. This test was also performed with $5 \mu \mathrm{L}$ of MM supernatant in which the cultures were grown after centrifugation at 15,000 rpm for 5 minutes. All the isolates were cultivated at least twice in the different media for this selection.

Surface tension assessment: Critical micellar concentration of biosurfactants (CMC) partially (i.e. supernatants and cell culture media) were estimated by surface tension quantification by the Du Nouy method [24]. Dilutions of culture media and their supernatants were prepared in water. the surface tension of the supernatant dilutions is quantified in tensiometer. CMC was estimated after plotting surface tension. versus medium dilution, such as the reciprocal of critical micellar dilution, in which the superficiality began to increase [24]. This evaluation was carried out with three repetitions for each isolate, each repetition was performed in triplicate.

\section{Analysis of biofilm formation}

In this study the bacteria S. aureus-ATCC 29213, E. coli-ATCC 25922 and E. cloacae sp on test discs in stainless steel and titaniumaluminum-vanadium to induce biofilm formation. These were aseptically inserted into culture tubes containing Mueller broth. Hinton $\AA$, the $108 \mathrm{CFU}$ ml- 1 bacterial test discs and suspensions incubated for 24 hours for the surfactin test and 72 hours for the rhamnolipids test under stirring at $37^{\circ} \mathrm{C}$. After incubation periods, the discs were removed from the médium culture and ultrasound bath in $5.0 \mathrm{ml}$ sterile physiological solution at $0.85 \%(\mathrm{w} / \mathrm{v})$. From then on, dilutions of the order of 10-1 The 10-4, quantifying the viable cells present and characterizing the formation of biofilm.

\section{Result and Discussion}

After production, partial purification of the studied biosurfactants and coating with them in the titanium and stainless steel specimens to then induce the formation of bacterial biofilms in those materials, it was possible to perceive inhibition of microbial cover formation to varying degrees depending on the type constituent material of the test specimens, bacterial species forming the biofilm, type and concentration of applied biosurfactant. After 24 hours of incubation, biofilm formation in the presence of surfactin biosurfactant was significantly reduced compared to control, as shown in Table 1. As shown, S. aureus, E. coli, and E. cloacae showed reductions in bacterial counts on specimens by up to $80 \%$, after surfactin application (Table 1 ). 
Table 1: Colony Forming Unit Counts for Each Milliliter (CFU.mL $\mathrm{mL}^{-1}$ ) for the control treatment (without the addition of surfactin) and for the diferente biosurfactant treatments at $0.1 \mathrm{mg} / \mathrm{ml} ; 1.0 \mathrm{mg} / \mathrm{ml}$ and $10.0 \mathrm{mg} / \mathrm{ml}$.

\begin{tabular}{|c|c|c|c|c|}
\hline \multicolumn{5}{|c|}{ Titanium Alloy } \\
\hline \multirow{2}{*}{ Bacteria } & \multirow{2}{*}{ Controls } & \multicolumn{3}{|c|}{ Biosurfactant Concentrations } \\
\hline & & $0,1 \mathrm{mg} / \mathrm{ml}$ & $1 \mathrm{mg} / \mathrm{ml}$ & $10 \mathrm{mg} / \mathrm{ml}$ \\
\hline E.coli & 13.5 & 12.6 & 8.2 & 4.8 \\
\hline E.cloacae & 5.6 & 4.3 & 3.9 & 3.3 \\
\hline S.aureus & 11.4 & 10.2 & 8.9 & 6.9 \\
\hline S.epidermidis & 9.9 & 9.6 & 8.4 & 4.2 \\
\hline \multicolumn{5}{|c|}{ Stainless Steel } \\
\hline \multirow{2}{*}{ Bacteria } & \multirow{2}{*}{ Controls } & \multicolumn{3}{|c|}{ Biosurfactant concentrations } \\
\hline & & $0,1 \mathrm{mg} / \mathrm{ml}$ & $1 \mathrm{mg} / \mathrm{ml}$ & $10 \mathrm{mg} / \mathrm{ml}$ \\
\hline E.coli & 30.6 & 28.3 & 8.9 & 5.7 \\
\hline E.cloacae & 11.2 & 10.1 & 4.8 & 4.1 \\
\hline S.aureus & 13.5 & 12.5 & 9.2 & 8 \\
\hline S.epidermidis & 13.8 & 12.5 & 9.4 & 7.5 \\
\hline
\end{tabular}

For the rhamnolipids biosurfactant produced by P. aeruginosa strain, a reduction in biofilm formation on the surface of the specimens was also observed. tested in the presence of that biosurfactant in relation to the control, as shown Table 2. For biofilms formed by S. aureus, E. coli and E. cloacae up to $72 \%$ inhibition of biofilm formation, especially S. aureus, important microorganism that causes nosocomial infections with reduction in stainless steel up to $68 \%$ (Table 2).

Table 2: Colony Forming Unit Counts (CFU mL-1) to control treatment (without addition of rhamnolipids) and for treatments with the addition of $0.1 \mathrm{mg} /$ $\mathrm{ml}$ rhamnolipids biosurfactant; $1.0 \mathrm{mg} / \mathrm{ml}$ and $10.0 \mathrm{mg} / \mathrm{ml}$.

\begin{tabular}{|c|c|c|c|c|}
\hline \multicolumn{5}{|c|}{ Titanium Alloy } \\
\hline \multirow{2}{*}{ Bacteria } & \multirow{2}{*}{ Controls } & \multicolumn{3}{|c|}{ Biosurfactant concentrations } \\
\hline & & $0,1 \mathrm{mg} / \mathrm{ml}$ & $1 \mathrm{mg} / \mathrm{ml}$ & $10 \mathrm{mg} / \mathrm{ml}$ \\
\hline E. coli & 12.95 & 12.8 & 9.5 & 7.1 \\
\hline E. cloacae & 6.5 & 5.9 & 4.6 & 4.1 \\
\hline S. aureus & 13.5 & 13.3 & 12.5 & 10.7 \\
\hline S. epidermidis & 8.6 & 8.2 & 4.15 & 2.6 \\
\hline \multicolumn{5}{|c|}{ Stainless Steel } \\
\hline \multirow{2}{*}{ Bacteria } & \multirow{2}{*}{ Controls } & \multicolumn{3}{|c|}{ Biosurfactant concentrations } \\
\hline & & $0,1 \mathrm{mg} / \mathrm{ml}$ & $1 \mathrm{mg} / \mathrm{ml}$ & $10 \mathrm{mg} / \mathrm{ml}$ \\
\hline E. coli & 27.8 & 26.2 & 22 & 18.3 \\
\hline E. cloacae & 13.3 & 11.5 & 8.1 & 5.4 \\
\hline S. aureus & 14.2 & 13.9 & 11 & 7.9 \\
\hline S. epidermidis & 12.1 & 11.8 & 6.4 & 4.3 \\
\hline
\end{tabular}

Through the direct counting method performed to quantifying the total bacterial cells adhered to the devices were found differences in the inhibition of biofilm formation between titanium alloy and steel stainless steel devices (Figure 1 and 2). This is probably due to associated virulence factors, adhesion, hydrophobicity as well as the outer membrane and the different degrees of electronegativity of bacterial cell walls and the presence of polar chemicals on their surface (Figure $1 \& 2$ ).

As shown in the Graph below (Graph 1), the tests performed with the surfactin to evaluate the anti-adhesive effect on titanium and steel specimens stainless steel, point to a trend towards greater biofilm formation in steel parts stainless (Graph 1).

For S. aureus and E. cloacae there are differences in the inhibition of biofilm formation to titanium alloy and stainless-steel devices in the presence of sufactin with silver nanoparticles. However, there is a trend towards higher biofilm formation in stainless steel devices (Graphic 2 \& 3).

Tests with rhamnolipids was performed to evaluate the antiadhesive effect on the devices. Was noticed that trend of higher biofilm formation in stainless steel devices compared to titanium alloy devices (Graphs 4 \& 5). 


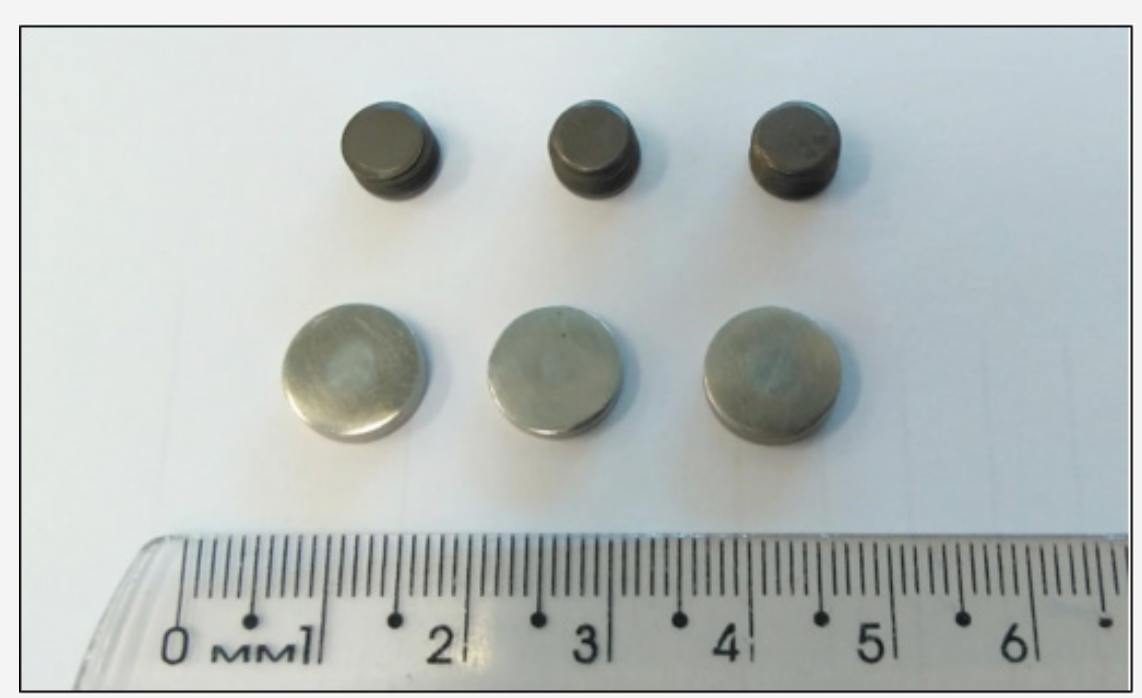

Figure 1: Fistulous

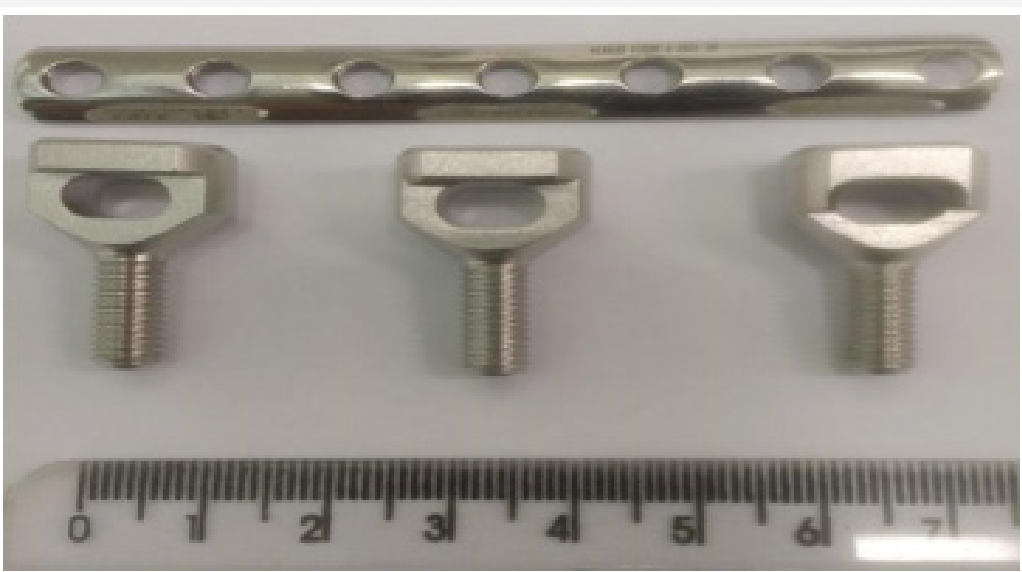

Figure 2: Titanium alloy and stainless-steel devices.

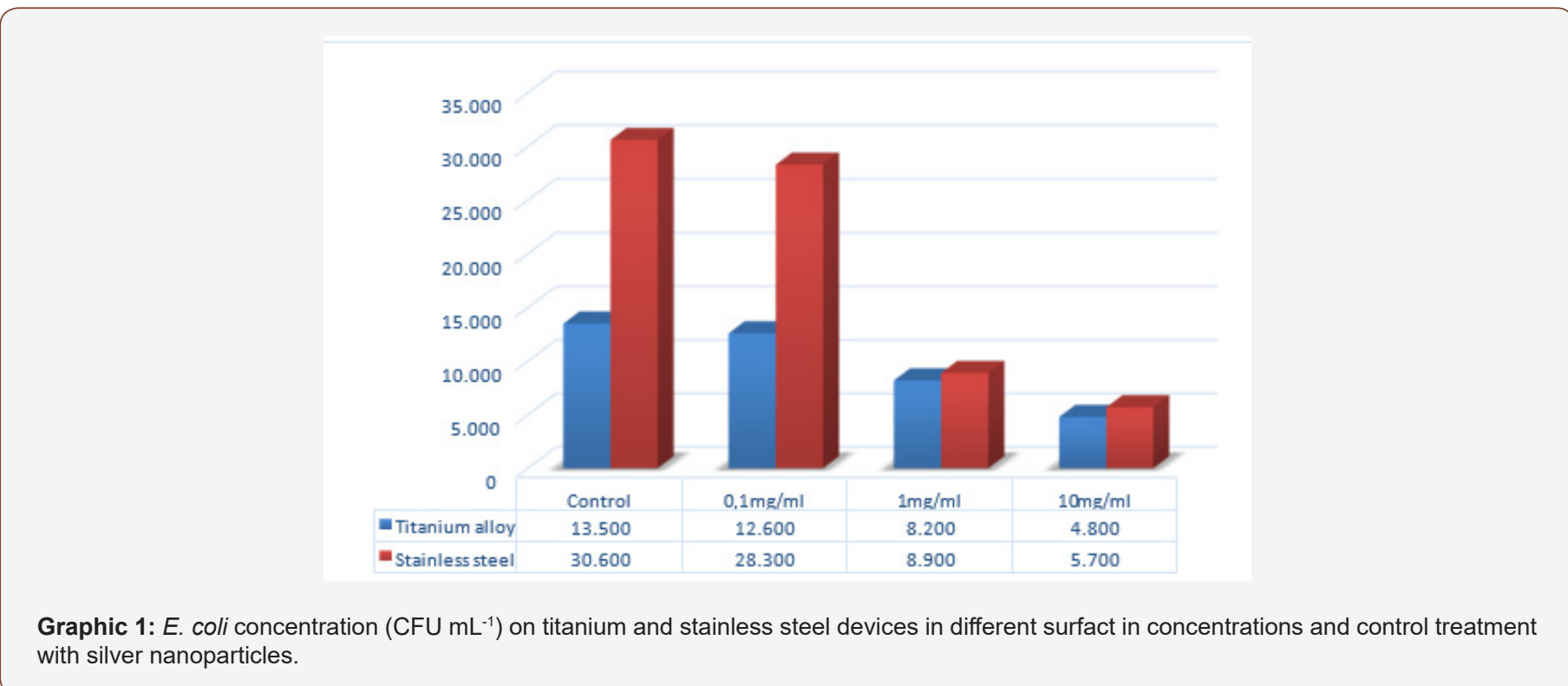




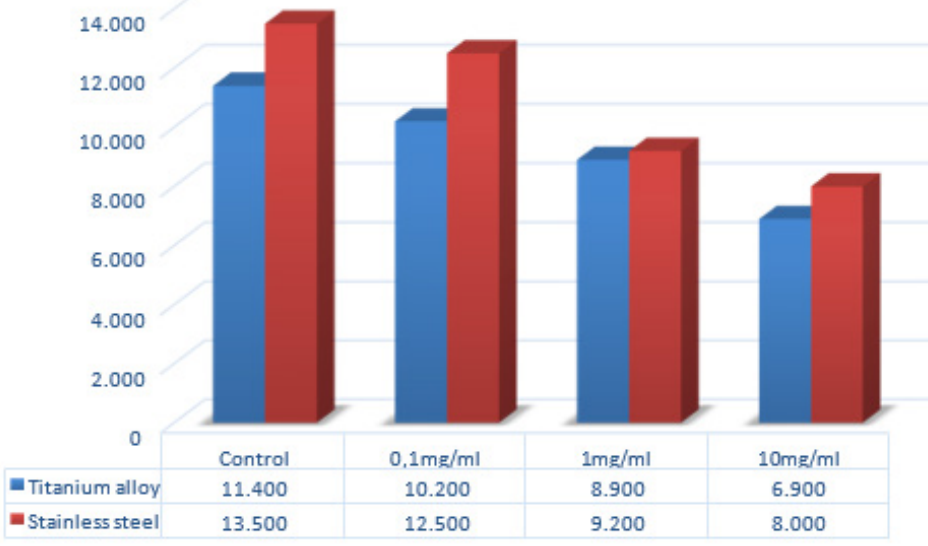

Graphic 2: Concentration of S.aureus (CFU mL-1) in titanium and stainless steel devices submitted to different surfactin concentrations with silver nanoparticles and control treatment.

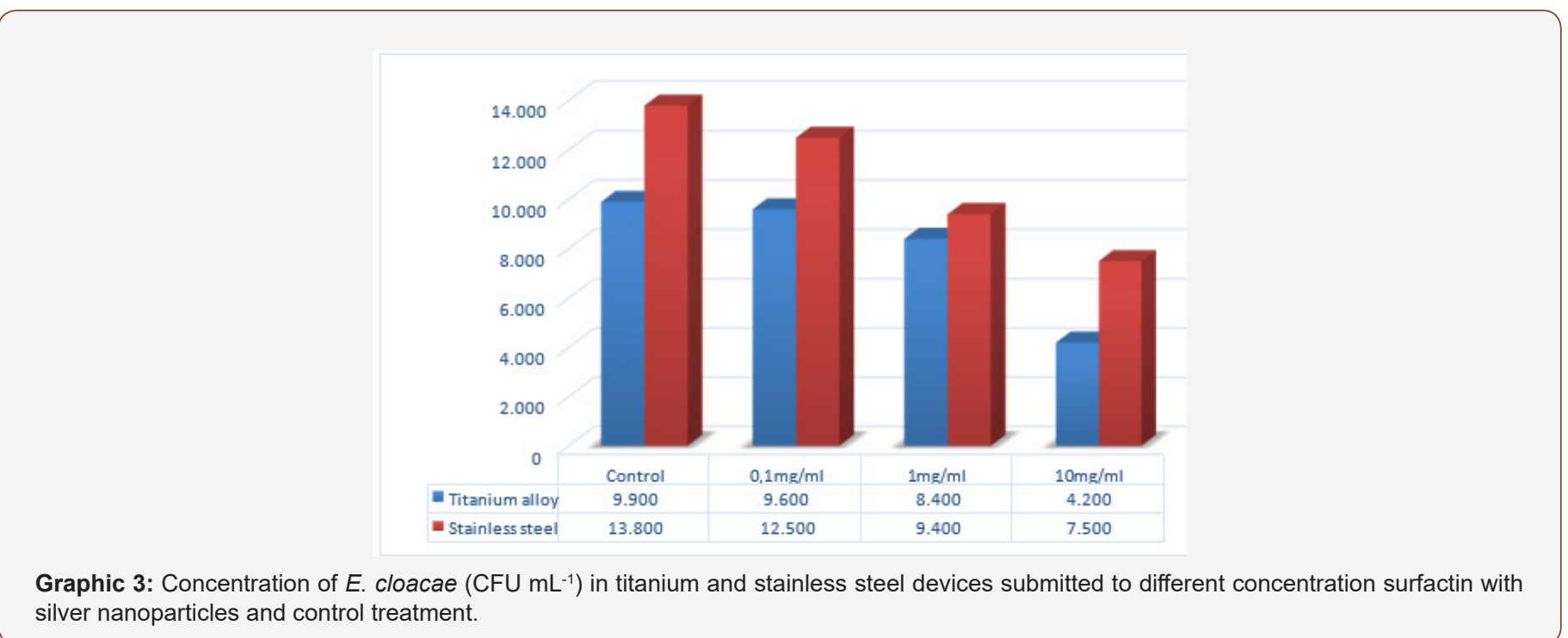

Graphic 3: Concentration of E. cloacae $(C F-$
silver nanoparticles and control treatment.

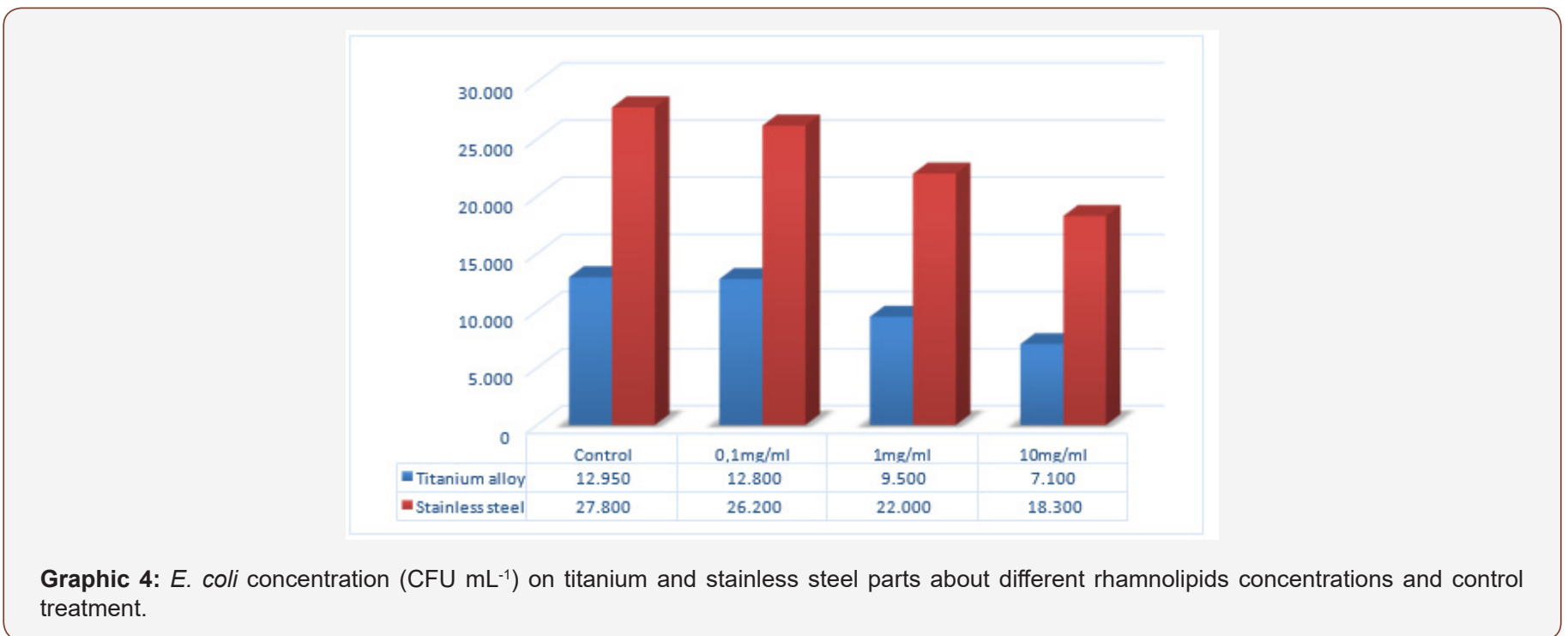




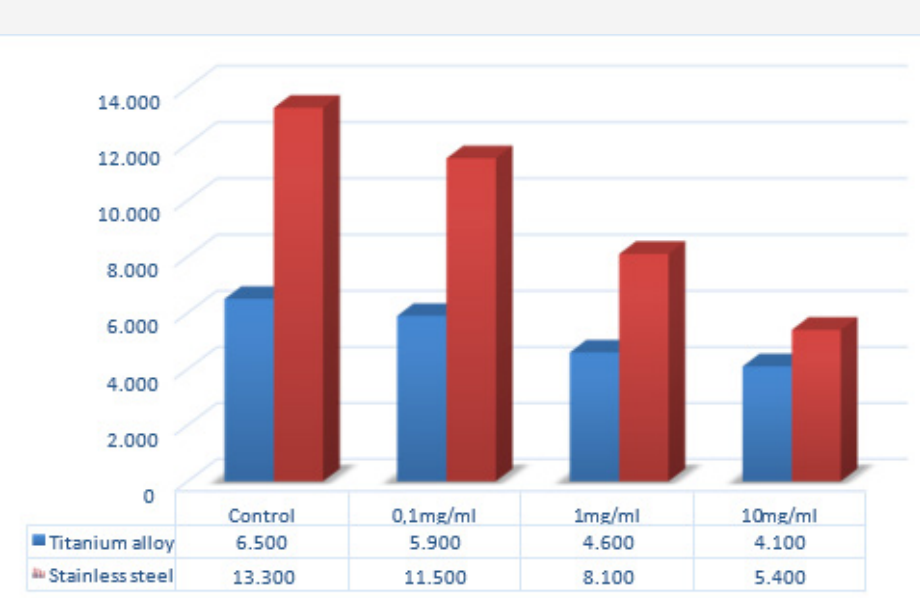

Graphic 5: S. aureus concentration (CFU. $\mathrm{mL}^{-1}$ ) in titanium and stainless steel devices submitted to different rhamnolipids concentrations and control treatment.

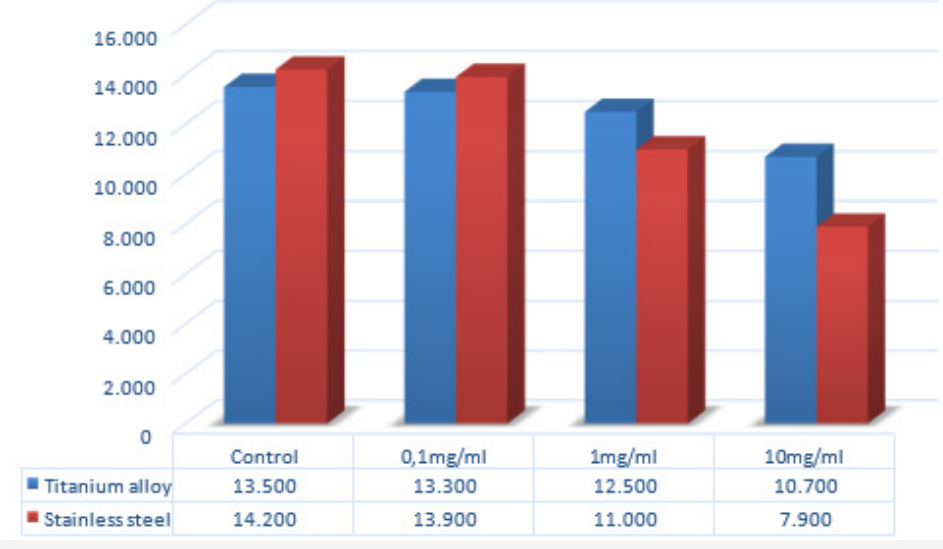

Graphic 6: S.aureus concentration (CFU mL-1) in titanium and stainless steel devices submitted to different concentrations of rhamnolipids and control treatment.

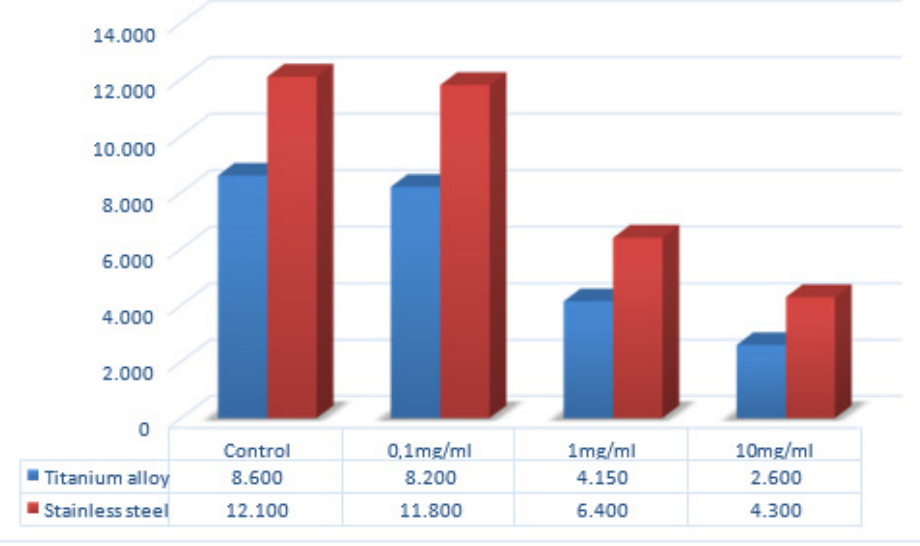

Graphic 7: Concentration of $E$. cloacae (CFU mL-1) in titanium and stainless steel devices submitted to different concentrations of rhamnolipids and control.

To S. aureus isolates the tendency of higher biofilm formation in stainless steel devices remained in the control treatment and 0.1 $\mathrm{mg} \mathrm{mL}^{-1}$ treatment with. In the case of for rhamnolipids to $1.0 \mathrm{mg}$
mL-1 and 10mg ml-1 it was observed that stainless steel devices showed greater inhibition of biofilm formation when compared to titanium alloy devices (Graph 6). 
For isolates of E. cloacae the tendency of greater biofilm formation in stainless steel devices remained in the control test as well for the different rhamnolipids concentrations (Graph 7).

\section{Conclusion}

Evaluating the anti-adhesive action of biofilm-forming bacteria from surfactin and rhamnolipids biosurfactants with silver nanoparticles obtained by green synthesis, we obtained very promising results in terms of inhibition of biofilm formation of $\mathrm{S}$. aureus, E. coli and E. cloacae. Best performance and best anti-biofilm feature for biosurfactant surfactin compared to rhamnolipids biosurfactant as well as higher formation and biofilms in stainless steel parts compared to titanium. The results are quite promising from a public health point of view. in view of the health problems and major damage to public health systems, resulting from biofilm formation in those types of implanted orthopedic materials.

\section{Acknowledgement}

None.

\section{Conflict of Interest}

The author reports no conflict of interest.

\section{References}

1. Bozic KJ, Ries MD (2005) The impact of infection after total hip arthroplasty on hospital and surgeon resource utilization. J Bone Joint Surg Am 87(8): 1746-1751.

2. Lentino J (2003) Prosthetic Joint Infections: Bane of Orthopedists, Challenge for Infectious Disease Specialists. Clinical Infectious Disease36(9) :1157-1161.

3. Ahnfelt L, Herberts P, Malchau H, Anderssonm GB (1990) Prognosis of total Hip Replacement. A Swedish multicenter study of 4664 revision. Acta Orthop Scand Suppl 238: 1-26.

4. Hanssen AD, Rand JA (1999) Evaluation and treatment of infection at the site of a total hip or knee arthroplasty. Instr Course Lect 48: 111-122.

5. Jarvis FG, Johnson MJ (1949) A glyco-lipide produced by Pseudomonas Aeruginosa. The Journal of the American Chemical Society 71(12): 4124-4126.

6. Salvati EA, Gonzalez Della Valle A, Duncan CP (2003) The infected total hip arthroplasty. Instr Cource Lect 52: 223-245.

7. Ehrlich GD, Paul Stoodley, Sandeep Kathju, Yongjun Zhao, et al. (2006) Engineering approaches for the detection and control of orthopaedic biofilm infections. Clin Orthop Relat Res (437) :59-66.
8. Maniasso N (2001) Micellar Environments in Analytical Chemistry. New Chemistry 24 (1):8793.

9. Nitschke M, Costa SGVO (2007) Biosurfactants in Food Industry. Trends in Food Science \& Technology 18(5) :252-259.

10. Costa SGVO, Nitschke M, Contiero C (2008) Production of biotensoactives from waste oils and fats. Food Science and Technology 28: 34-38.

11. Barros FFC, Quadros CP, Maróstica MRJ, Pastore GM (2007) Surfactin: Pumice, technological and functional properties for food applications. Química Nova 30(2): 409-414.

12. Costerton JW, Stewart PS, Greenberg EP (1999) Bacterial Biofilms: A Common Cause of Persistent Infections. Science 284(5418) : 1318-1322.

13. Darouiche RO (2004) Treatment of infections associated with surgical implants. The N Engl J Med 350(14): 1422-1429.

14. Lucke M, G Schmidmaier, S Sadoni, B Wildemann, R Schiller, et al. (2003) Gentamicin coating of metallic implants reduces omplantrelated osteomyelitis in rats. Bone 32(5): 521-531.

15. Sanderson PJ (1989) Preventing infection in orthopaedic implants. Journal of Antimicrobial Chemotherapy 24: 277-280.

16. Taylor GJ, Bannister GC, Calder S (1990) Perioperative wound infection in eletive orthopaedic surgery. J Hosp Infect

16(3): 241-247.

17. Wilde AH (1993) Management of infected knee and hip prostheses. Curr Opin Rheumato 5(3): 317-321.

18. Zhao Q, Y Liua, C Wanga, S Wanga, N Peng, et al. (2007) Bacterial adhesion on ion-implanted stainless-steel surfaces. Applied Surface Science 253(21): 8674-8681.

19. Zhao Q, Y Liu, C Wang, S Wang, N Peng, et al. (2008) Reduction of bacterial adhesion on ion-implanted stainless steel Surfaces. Medical Engineering \& Physics, 30(3): 341-349.

20. Barth E, Myrvik QM, Wagner W, Gristina AG (1989) In vitro and in vivo comparative colonization of Staphylococcus aureus and Staphylococcus epidermidis on orthopaedi implant materials. Biomaterials 10(5): 325328.

21. Bernardi ACA (2005) Study of coagulase-negative Staphylococcus samples for biofilm formation. Thesis (doctorate)- Faculty of Pharmaceutical Sciences, Universidade Estadual Paulista, Araraquara.

22. Carek PJ, Dickerson LM, Sack JL (2001) Diagnosis and management of osteomyelitis. Am Fam Physician 63(12):2413-2420.

23. Bodour AA, Miller-Maier R (1998) Application of a modified dropcollapse technique for surfactante quantitation and screening of biossurfactant producing. Journal of Microbiological Methods 32: 273280.

24. Cooper DG, Zajic JE, Gerson DF (1979) Production of surface-active lipids by Corynebacterium lepus. Appl Environ Microbiol 37(1): 4-10. 